\title{
Kinetics of styrene emulsion polymerization in the presence of montmorillonite
}

\author{
Chorng-Shyan Chern ${ }^{\mathrm{a}, *}$, Jiang-Jen Lin ${ }^{\mathrm{b}}$, Yan-Liang Lin ${ }^{\mathrm{a}}$, Shu-Zhen Lai ${ }^{\text {a }}$ \\ ${ }^{a}$ Department of Chemical Engineering, National Taiwan University of Science and Technology, Taipei 106, Taiwan, ROC \\ ${ }^{\mathrm{b}}$ Institute of Polymer Science and Engineering, National Taiwan University, Taipei 106, Taiwan, ROC
}

Received 5 September 2005; received in revised form 31 October 2005; accepted 2 November 2005

Available online 22 December 2005

\begin{abstract}
The effect of the pristine sodium montmorillonite $\left(\mathrm{Na}^{+}-\mathrm{MMT}\right)$ on the styrene emulsion polymerizations with different concentrations of SDS ([SDS]) was investigated. At constant [SDS], the polymerization rate is faster for the run with $1 \mathrm{wt} . \% \mathrm{Na}^{+}$-MMT compared to the counterpart without $\mathrm{Na}^{+}$-MMT. Micelle nucleation predominates in the polymerizations with $[\mathrm{SDS}] \geqq 13 \mathrm{mM}$. On the other hand, the contribution of the polymerization associated with the $\mathrm{Na}^{+}-\mathrm{MMT}^{-}$ platelets increases significantly when [SDS] decreases from 13 to $9 \mathrm{mM}$. At [SDS] (e.g., $2 \mathrm{mM}$ ) $<$ CMC, homogeneous nucleation controls the particle formation process and polymerization kinetics. Moreover, the contribution of the $\mathrm{Na}^{+}-$ MMT platelets that act as extra reaction loci to the polymerization kinetics is even comparable to the run in the absence of $\mathrm{Na}^{+}$-MMT. The resultant polymer particle size, polymer molecular weight and zeta potential were characterized and a preliminary model was developed to qualitatively study the differences between the polymerizations in the presence and absence of $1 \mathrm{wt} . \% \mathrm{Na}^{+}$-MMT.
\end{abstract}

(c) 2005 Elsevier Ltd. All rights reserved.

Keywords: Styrene emulsion polymerization; Montmorillonite; Kinetics

\section{Introduction}

Emulsion polymerization involves the propagation reaction of free radicals with monomer within the monomer-swollen polymer particles dispersed in the continuous aqueous phase. The discrete hydrophobic particles are stabilized by surfactant such as the anionic sodium dodecyl sulfate (SDS). When the level of surfactant is greater than its critical micelle concentration (CMC), the polymeriza-

\footnotetext{
* Corresponding author. Tel.: +886 2 27376649; fax: +886 2 27376644.

E-mail address: cschern@mail.ntust.edu.tw (C.-S. Chern).
}

tion kinetics can be adequately predicted by the Smith-Ewart theory [1-6]. Particle nuclei are generated via the capture of radicals by micelles, termed the micelle nucleation. On the other hand, the polymerization with the surfactant concentration below its CMC is characterized by homogeneous nucleation [7-11]. The water-borne radical becomes insoluble and forms a particle nucleus when a critical chain length is achieved. This is followed by the formation of stable primary particles via the limited flocculation of unstable particle nuclei and adsorption of surfactant on their particle surfaces. The rate of polymerization $\left(R_{\mathrm{p}}\right)$ is linearly proportional to the number of particles nucleated per liter water 
$\left(N_{\mathrm{p}}\right)$ and average number of radicals per particle $(n)$ : $R_{\mathrm{p}}=k_{\mathrm{p}}[\mathrm{M}]_{\mathrm{p}}\left(n N_{\mathrm{p}} / N_{\mathrm{A}}\right)$, where $k_{\mathrm{p}}$ is the propagation rate constant, $[\mathrm{M}]_{\mathrm{p}}$ is the concentration of monomer in the particles and $N_{\mathrm{A}}$ is the Avogadro number.

Inorganic materials such as the cost effective sodium montmorillonite $\left(\mathrm{Na}^{+}-\mathrm{MMT}\right)$ are generally added into latex products to improve their physical properties. Recently, emulsion polymerizations of various monomers in the presence of $\mathrm{Na}^{+}-\mathrm{MMT}$ were investigated and the resultant composite materials characterized [12-16]. Kim et al. [14] prepared intercalated hydrophobic polystyrene (PS)/ $\mathrm{Na}^{+}$MMT composite particles via emulsion polymerization without resort to the ionic exchanging process. It was shown that emulsion polymerization is an effective process for synthesizing the intercalated $\mathrm{PS} / \mathrm{Na}^{+}$-MMT particles. This is due to the fact that the interlayers of $\mathrm{Na}^{+}-\mathrm{MMT}$ are filled with $\mathrm{Na}^{+}$ions and, therefore, the hydrophilic $\mathrm{Na}^{+}$-MMT platelets are highly swollen in water. This will then promote the penetration of the water-borne oligomeric radicals into the multiple-layered $\mathrm{Na}^{+}-\mathrm{MMT}$. However, to the best of our knowledge, the literature dealing with the kinetics of the styrene (ST) emulsion polymerization in the presence of $\mathrm{Na}^{+}$-MMT is nil. The goal of this work was therefore to gain a better understanding of the role of $\mathrm{Na}^{+}$-MMT in the ST emulsion polymerization initiated by sodium persulfate (SPS) and stabilized by SDS.

\section{Experimental}

\subsection{Materials}

ST (Taiwan Styrene), $\mathrm{Na}^{+}-\mathrm{MMT}$ (Kunimine Ind., a smectite silicate clay with a cationic exchange capacity of $1.15 \mathrm{meq} \mathrm{g}^{-1}$ ), SDS (J.T. Baker, 99\%), SPS (Riedel-de Haen), sodium bicarbonate (Janssen Chimica), hydroquinone (Nacalia Tesque), sodium chloride (J.T. Baker), methanol (Acros), a series of PS standards for GPC calibration (Shodex), tetrahydrofuran (THF; Merk), nitrogen (Ching-FengHarng), and deionized water (Barnsted Nanopure Ultrapure Water System, specific conductance $<0.057 \mu \mathrm{S} \mathrm{cm}^{-1}$ ) were used in this work. ST was distilled at $40{ }^{\circ} \mathrm{C}$ under reduced pressure. All other chemicals were used as received.

\subsection{Experimental methods}

The CMC of the aqueous solution of SDS in the presence or absence of $\mathrm{Na}^{+}-\mathrm{MMT}$ was determined by the electric conductance technique (Orion, Model 115) [17-19]. The concentrations of $\mathrm{NaHCO}_{3}$ (buffer) and $\mathrm{Na}^{+}$-MMT were set at $2.59 \mathrm{mM}$ and $1 \mathrm{wt} . \%$, respectively, in the conductivity measurements. For the $\mathrm{Na}^{+}-\mathrm{MMT}$ suspension, the sample was first subject to ultrasonication (Ultrasonics, Sonicator W385) for $15 \mathrm{~min}$ and it was then stirred using a $45^{\circ}$-pitched 4-bladed agitator at $200 \mathrm{rpm}$ and $30{ }^{\circ} \mathrm{C}$ for $20 \mathrm{~min}$. Note that the suspension at the time of the conductivity measurement was kinetically stable. Thus, 1 min before the start of measurement, the agitation was stopped and the average of three measurements at $0.5,1$ and $1.5 \mathrm{~min}$ was reported as the conductivity $(\kappa)$. The above procedure was repeated for different concentrations of SDS [SDS]. The CMC was then determined from the break of the slope on the $\kappa$ vs. [SDS] curve.

To assure the uniformity and reproducibility of the suspensions in emulsion polymerization experiments, the pristine clay was added slowly to the mixture containing $\mathrm{H}_{2} \mathrm{O}, \mathrm{NaHCO}_{3}$ and SDS with the aid of a mechanical homogenizer (Janke \& Kunkel, Ultra-Turrax T25) operated at 8000, 9500 and then $13500 \mathrm{rpm}$ (10 min for each homogenization step). This was followed by charging the $\mathrm{Na}^{+}$-MMT suspension and ST in sequence to a $750-\mathrm{ml}$ reactor equipped with a $45^{\circ}$-pitched 4-bladed agitator, a thermometer, and a reflux condenser. The reaction mixture was purged with $\mathrm{N}_{2}$ to remove the dissolved $\mathrm{O}_{2}$ for $30 \mathrm{~min}$ before the start of polymerization initiated by $2.59 \mathrm{mM}$ SPS. The temperature was controlled within $70 \pm 0.5^{\circ} \mathrm{C}$ and the agitation speed was kept constant at $250 \mathrm{rpm}$ throughout the reaction. The total solid content of the latex product is about $16 \%$ for complete monomer conversion. The product was filtered through 40 -mesh $(0.42 \mathrm{~mm})$ and 200 -mesh $(0.074 \mathrm{~mm})$ screens in series to collect filterable solids. Scraps adhering to the agitator, thermometer, and reactor wall were also collected. The levels of filterable solids and scraps obtained from all the polymerizations were negligible. These results showed that satisfactory colloidal stability during the reaction was achieved for the recipes and polymerization conditions used in this work. The total solid content and conversion of $\mathrm{ST}(X)$ were determined gravimetrically. The weight-average particle diameter $\left(d_{\mathrm{w}}\right)$, volume-average particle diameter $\left(d_{\mathrm{v}}\right)$ and polydispersity index of the particle size distribution ( $\mathrm{PDI}=d_{\mathrm{w}} / d_{n}$ ) were measured by transmission electron microscopy (TEM, JEOL TEM-1200 EXII). The parameter $d_{n}$ is the num- 
ber-average particle diameter. At least 300 spherical particles per sample were counted in the particle size measurement. Based on the $d_{\mathrm{v}}$ data, the number of particles per liter water produced at the end of polymerization without $\mathrm{Na}^{+}$-MMT $\left(N_{\mathrm{p}}\right)$ was calculated.

The zeta potential of colloidal particles $(\zeta)$ was measured with the Malvern Zetamaster. The dilution solution for the sample (total solid content $=0.01 \%$ ) was $0.01 \mathrm{M} \mathrm{NaCl}$. The reported $\zeta$ data represent an average of at least 10 measurements. Latex particles were precipitated by an excess of methanol, followed by thorough washes with methanol and water to remove residual SDS and other impurities. The dried $\mathrm{PS} / \mathrm{Na}^{+}-\mathrm{MMT}$ composite was dissolved in THF $\left(\approx 2 \times 10^{-3}\right.$ $\left.\mathrm{g} \mathrm{cm}^{-3}\right)$. The weight-average polymer molecular weight $\left(M_{\mathrm{w}}\right)$ was determined by gel permeation chromatography (GPC; Waters 515/2410/Styragel HR2, HR4, and HR6) calibrated by a series of PS standards (Shodex). The sample was filtered by a $0.45 \mu \mathrm{m}$ membrane immediately before the GPC measurement. X-ray powder diffraction (XRD) analysis was performed by a diffractometer (MAC Science MXP18) with a $\mathrm{Cu}$ target $(\lambda=1.54 \times$ $10^{-10} \mathrm{~m}$ ) at a generator voltage of $30 \mathrm{kV}$, a generator current of $25 \mathrm{~mA}$, and a scanning rate of $4^{\circ} \min ^{-1}$.

\section{Results and discussion}

Representative $\kappa$ vs. [SDS] data are shown in Fig. 1. The CMC of the aqueous solution of SDS and $2.59 \mathrm{mM} \mathrm{NaHCO}$ is $8.3 \mathrm{mM}$, which is very close to those of the aqueous SDS solutions in the absence of $\mathrm{NaHCO}_{3}[20,21]$. However, incorporation of $1 \mathrm{wt} . \% \mathrm{Na}^{+}-\mathrm{MMT}$ reduces the CMC to $6.4 \mathrm{mM}$. This implies that the $\mathrm{Na}^{+}$-MMT platelet surfaces are relatively hydrophilic and, thus, not effective for the adsorption of SDS. Another factor is the much higher ionic strength of the $\mathrm{Na}^{+}$-MMTcontaining SDS solution compared to the native SDS solution, as shown by the magnitudes of the $\kappa$ data in Fig. 1. SDS molecules subject to the hostile environment with a very high electrolyte concentration show a stronger tendency to aggregate with one another to form micelles. This will then result in the decreased $\mathrm{CMC}$. The $\mathrm{CMC}$ values are expected to have an influence on the concentration of micelles available for particle nucleation (i.e., polymerization kinetics).

Representative $X$ vs. time $(t)$ curves for the ST emulsion polymerizations in the presence of

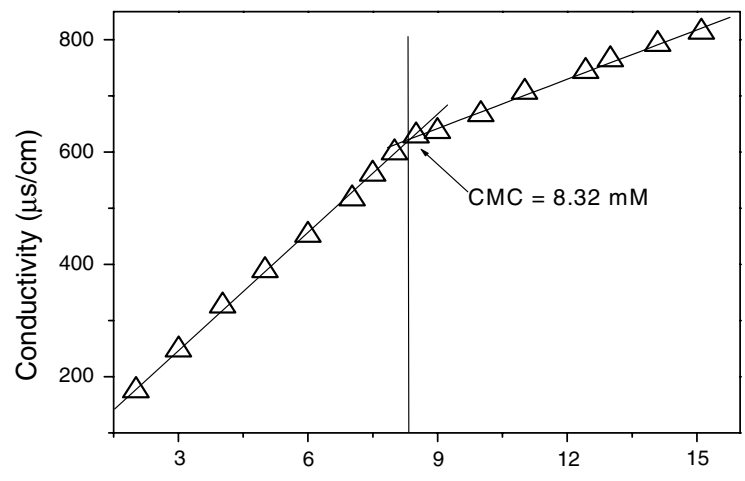

(a)

[SDS] (mM)

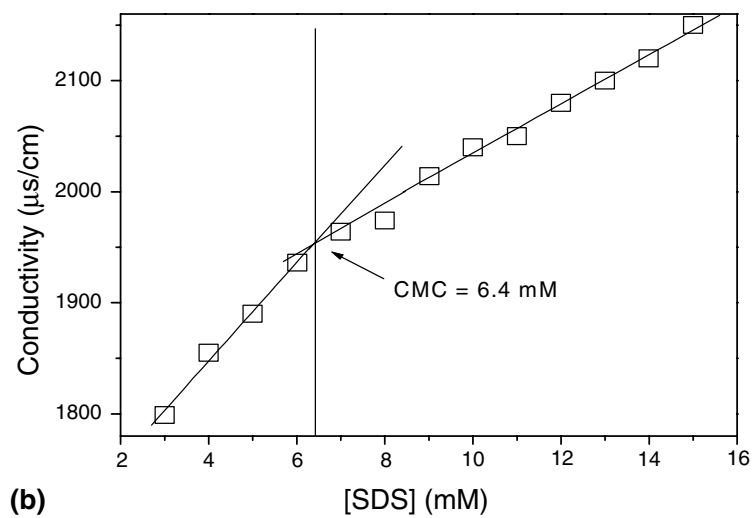

Fig. 1. Specific conductivity of SDS as a function of the bulk SDS concentration. (a) SDS; (b) SDS +1 wt. $\% \mathrm{Na}^{+}-\mathrm{MMT}$.

1 wt. $\% \mathrm{Na}^{+}$-MMT and 2-19 mM SDS are shown in Fig. 2. For comparison, in the absence of $\mathrm{Na}^{+}-$ MMT, the ST emulsion polymerization with $[\mathrm{SDS}]=2 \mathrm{mM}$ is also included in Fig. 2b. The experiment was carried out twice and the reproducibility was quite satisfactory. The rate of polymerization $\left(R_{\mathrm{p}}=[\mathrm{M}]_{0} \mathrm{~d} X / \mathrm{d} t\right)$ data as a function of [SDS $]$ are shown in Fig. 3, where $[\mathrm{M}]_{0}$ is the initial monomer concentration based on total water $(1.7 \mathrm{M})$ and the value of $\mathrm{d} X / \mathrm{d} t$ is obtained from the least-squares-best-fitted slope of the linear portion of the $X$ vs. $t$ curve. The range of the kinetic data used to determine the value of $\mathrm{d} X / \mathrm{d} t$ was dependent on [SDS] due to the different particle nucleation periods and gel effects associated with different particle sizes at high conversion. The correlations based on the kinetic data are $R_{\mathrm{p}} \sim[\mathrm{SDS}]^{0.79}$ [coefficient of determination $\left(r^{2}\right)=0.9595$ ] and $R_{\mathrm{p}} \sim[\mathrm{SDS}]^{0.85}\left(r^{2}=0.9667\right)$ for the runs with and without $1 \mathrm{wt} . \% \mathrm{Na}^{+}$-MMT, respectively. At constant [SDS], $R_{\mathrm{p}}$ is faster for the run containing $\mathrm{Na}^{+}$MMT compared to the counterpart without $\mathrm{Na}^{+}$MMT. The enhanced $R_{\mathrm{p}}$ for the polymerizations 

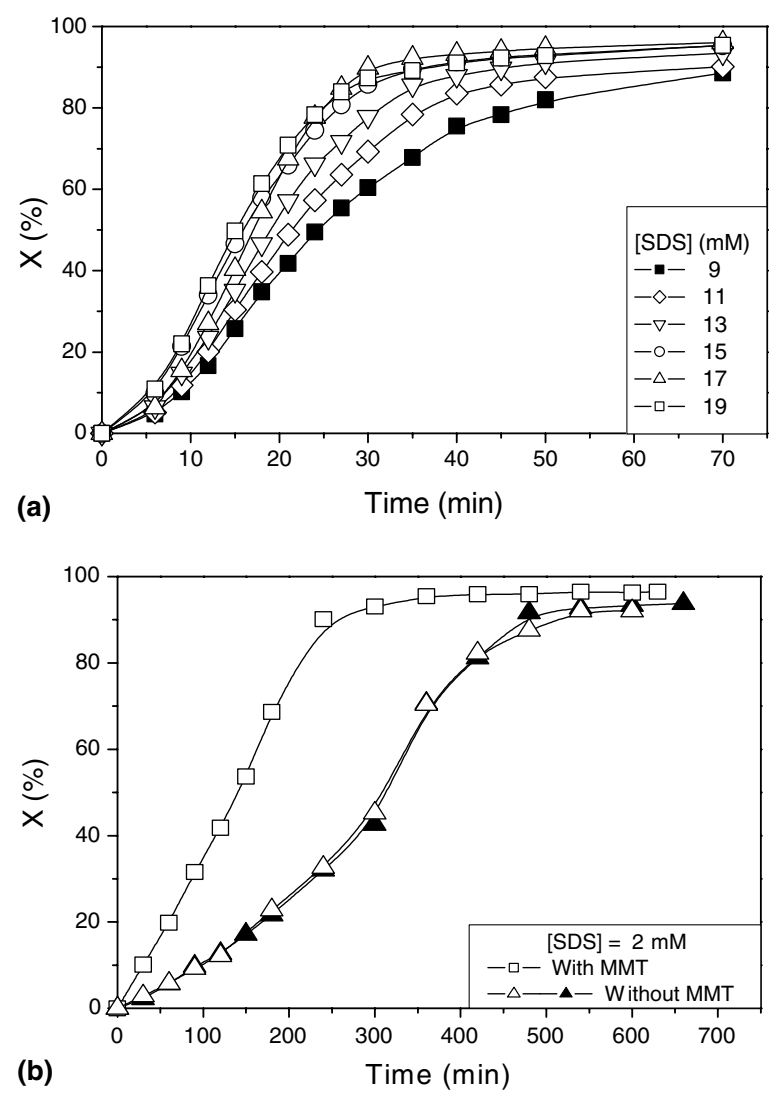

Fig. 2. Conversion as a function of time for the ST emulsion polymerizations in the presence of $1 \mathrm{wt} . \% \mathrm{Na}^{+}-\mathrm{MMT}$ and various bulk SDS concentrations. (a) $[\mathrm{SDS}](\mathrm{mM})=(\square)$ 19,

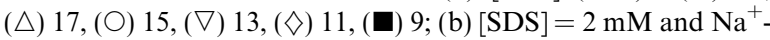
$\operatorname{MMT}($ wt. $\%)=(\square) 1,(\triangle, \mathbf{\Delta}) 0$.

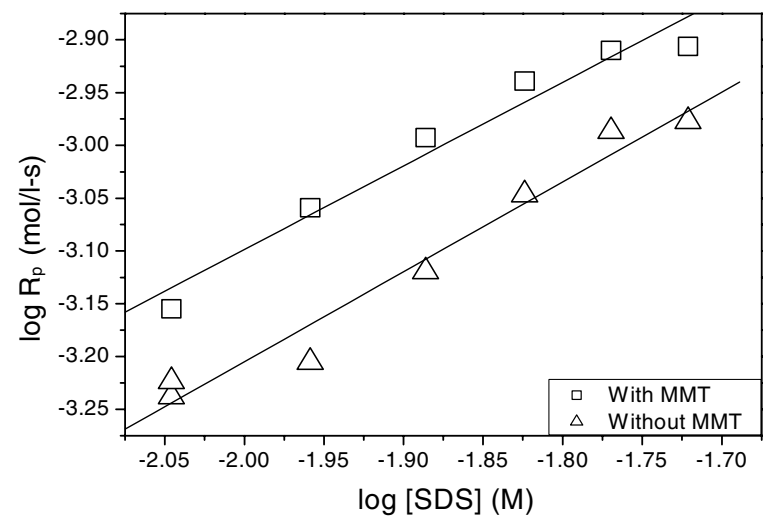

Fig. 3. Rate of polymerization as a function of the bulk SDS concentration. $\mathrm{Na}^{+}$-MMT (wt. $\left.\%\right)=(\square) 1,(\triangle) 0$.

containing $\mathrm{Na}^{+}$-MMT might be due to the larger number of micelles $\left(N_{\mathrm{m}}\right)$ available for particle nucleation provided that $[\mathrm{SDS}]$ is above its CMC. Chang et al. [19] showed that the fraction of SDS adsorbed on the ST droplet surfaces is insignificant compared to that associated with the monomer-swollen micelles. The data of the aggregation number of SDS molecules per micelle $\left(n_{\mathrm{agg}, \mathrm{m}}\right)$ obtained from the literature [22] follow the following leastsquares-best-fitted relationship:

$n_{\mathrm{agg}, \mathrm{m}}=83.201[\mathrm{NaCl}]+94.295 \quad\left(r^{2}=0.7705\right)$

where $[\mathrm{NaCl}]$ is the sodium chloride concentration. Although the data are somewhat scattered, about $33 \%$ increase in $n_{\text {agg,m }}$ is obtained when $[\mathrm{NaCl}]$ increases from 0.02 to $0.4 \mathrm{M}$ (i.e., a twentyfold increase in $[\mathrm{NaCl}])$. Fig. 1 shows that, for example, the conductivity (or ionic strength) of the aqueous SDS solution in the presence of $1 \mathrm{wt} . \% \mathrm{Na}^{+}$-MMT at $\mathrm{CMC}$ is only about three times as large as that of the aqueous SDS solution at CMC. Thus, the values of $n_{\mathrm{agg}, \mathrm{m}}$ should not change much for the polymerization recipes investigated in this study. To simplify the following estimation, the effect of ionic strength on $n_{\mathrm{agg}, \mathrm{m}}$ is neglected at this moment. Further assuming that the fraction of SDS adsorbed on both the monomer droplet surfaces and $1 \mathrm{wt} . \%$ $\mathrm{Na}^{+}$-MMT platelet surfaces is negligible and taking the polymerization with $[\mathrm{SDS}]=13 \mathrm{mM}$ as an example, the maximal increase of $N_{\mathrm{m}}$ due to the presence of $1 \mathrm{wt} . \% \mathrm{Na}^{+}$-MMT is $[(13-6.4) /(13-$ $8.3)-1] \times 100 \%=40 \%$ (Table 1 ). The corresponding increase of $R_{\mathrm{p}}$ due to the presence of $1 \mathrm{wt} . \%$ $\mathrm{Na}^{+}-\mathrm{MMT}$ is $\left[\left(9.97 \times 10^{-4}-7.60 \times 10^{-4}\right) / 7.60 \times\right.$ $\left.10^{-4}\right] \times 100 \%=31 \%$. Table 1 shows that micelle nucleation plays an important role in the polymerizations with $[\mathrm{SDS}] \geqq 13 \mathrm{mM}$. On the other hand, other parameters must come into play for the polymerizations with [SDS] $<13 \mathrm{mM}$, especially for the run with $[\mathrm{SDS}]=2 \mathrm{mM}$.

$R_{\mathrm{p}}$ is linearly proportional to the product of the number of reaction loci $\left(N_{\mathrm{p}}\right)$ and the average number of radicals per particle $(n) . N_{\mathrm{p}}$ is primarily determined by the concentration of micelles available for particle nucleation for the polymerizations with [SDS] $>$ CMC. In the absence of micelles, $N_{\mathrm{p}}$ is controlled by the amount of SDS available for stabilizing the particles generated by homogeneous nucleation. Fig. 4 shows (a) a representative TEM photograph for the $\mathrm{Na}^{+}$-MMT-containing polymerization with $[\mathrm{SDS}]=13 \mathrm{mM}$, (b) the final latex particle diameter $\left(d_{\mathrm{v}}\right)$ and (c) the particle size distribution (PDI) as a function of [SDS]. It is shown that $d_{\mathrm{v}}$ decreases with increasing [SDS] for both the polymerizations with and without $\mathrm{Na}^{+}$-MMT. At 
Table 1

Theoretical calculation of the maximal increase of $N_{\mathrm{m}}$ and the corresponding increase of $R_{\mathrm{p}}$ due to the presence of $1 \mathrm{wt} . \% \mathrm{Na}{ }^{+}$-MMT for ST emulsion polymerization

\begin{tabular}{lllllll}
\hline$[\mathrm{SDS}](\mathrm{mM})$ & 2 & 9 & 11 & 13 & 15 & 17 \\
\hline$\left[([\mathrm{SDS}]-\mathrm{CMC}) /\left([\mathrm{SDS}]-\mathrm{CMC}_{0}\right)-1\right] \times 100 \%^{\mathrm{a}}$ & - & 271 & 70 & 40 & 28 & 22 \\
$\left(R_{\mathrm{p}}-R_{\mathrm{p}, 0}\right) / R_{\mathrm{p}, 0} \times 100 \%{ }^{\mathrm{b}}$ & 113 & 17 & 40 & 31 & 28 & 14 \\
\hline
\end{tabular}

${ }^{\text {a }} \mathrm{CMC}$ and $\mathrm{CMC}_{0}$ represent the critical micelle concentration in the presence of and in the absence of $\mathrm{Na}^{+}$-MMT, respectively.

${ }^{\mathrm{b}} R_{\mathrm{p}}$ and $R_{\mathrm{p}, 0}$ represent the polymerization rate in the presence of and in the absence of Na+-MMT, respectively.

constant [SDS], the run with $\mathrm{Na}^{+}$-MMT has a smaller particle size compared to the counterpart without $\mathrm{Na}^{+}$-MMT. This is attributed to the larger population of particles originating from micelle nucleation as a result of the lowered CMC along with the smaller fraction of polymer produced in these particles. PDI increases slightly with increasing [SDS] for the polymerizations with $\mathrm{Na}^{+}$-MMT, but it remains relatively constant for the polymerizations without $\mathrm{Na}^{+}$-MMT. For constant polymer weight, $N_{\mathrm{p}}$ is inversely proportional to $d_{\mathrm{v}}$. Without the knowledge of the fraction of polymer produced in the particles originating from micelle nucleation, we were unable to obtain the $N_{\mathrm{p}}$ data from TEM measurements because the propagation reaction of radicals with monomer in the $\mathrm{Na}^{+}$-MMT platelets cannot be ignored [16]. Independent experiments are required to differentiate the polymer chains produced in the particles originating from micelle nucleation and those produced in the $\mathrm{Na}^{+}$-MMT platelets. It is postulated that the reaction systems with $[\mathrm{SDS}] \geqq 13 \mathrm{mM}$ are so abundant in micelles that the polymerization kinetics is predominated by micelle nucleation. Under the circumstances, the contribution of $\mathrm{Na}^{+}$-MMT platelets to the polymerization kinetics is not important. At [SDS] $<13 \mathrm{mM}$, on the other hand, the contribution of the polymerization associated with $\mathrm{Na}^{+}$-MMT platelets increases significantly when [SDS] decreases from 13 to $9 \mathrm{mM}$. At $[\mathrm{SDS}]=2 \mathrm{mM}$, micelles do not exist in the polymerization system. It is therefore the homogeneous nucleation that controls the polymerization kinetics. The contribution of $\mathrm{Na}^{+}-\mathrm{MMT}$ platelets to the polymerization kinetics is now even comparable to the run without $\mathrm{Na}^{+}$-MMT $\left(R_{\mathrm{p}}=4.80 \times 10^{-5} \mathrm{~mol} \mathrm{dm}^{-3} \mathrm{~s}^{-1}\right)$ provided that, as a first approximation, the contribution of $\mathrm{Na}^{+}$MMT platelets can be estimated to be the difference between the polymerization rate in the presence of $\mathrm{Na}^{+}$-MMT $\left(R_{\mathrm{p}}=1.02 \times 10^{-4} \mathrm{~mol} \mathrm{dm}^{-3} \mathrm{~s}^{-1}\right)$ and the polymerization rate in the absence of $\mathrm{Na}^{+}$MMT (i.e., $1.02 \times 10^{-4}-4.80 \times 10^{-5}=5.4 \times 10^{-5}$ mol $\mathrm{dm}^{-3} \mathrm{~s}^{-1}$ ). Fig. $2 \mathrm{~b}$ shows that $\mathrm{Na}^{+}$-MMT has a significant effect on the reaction kinetics, especially during the early stage of polymerization. At $[\mathrm{SDS}]<\mathrm{CMC}$, the formation of particle nuclei via homogeneous nucleation is very slow, as shown by the $X$ vs. $t$ data for the polymerization in the absence of $\mathrm{Na}^{+}$-MMT in Fig. 2b. By contrast, the polymerization in the presence of $\mathrm{Na}^{+}$-MMT does not exhibit the characteristic of slow $R_{\mathrm{p}}$. This implies that $\mathrm{Na}^{+}$MMT platelets serve as additional reaction loci for the propagation reaction of radicals with monomer and they predominate in the early stage of polymerization.

In comparison with the run with $9 \mathrm{mM}$ SDS and 1 wt. $\% \mathrm{Na}^{+}$-MMT, the polymerization with $9 \mathrm{mM}$ SDS and comparable ionic strength or conductivity (2000-2010 $\mu \mathrm{S} \mathrm{cm}^{-1}$, see the specific conductivity vs. [SDS] data in Fig. 1b) but in the absence of $\mathrm{Na}^{+}$-MMT was carried out to verify the proposed polymerization mechanisms. The increased conductivity of the polymerization system without $\mathrm{Na}^{+}$MMT was achieved by the addition of $\mathrm{NaCl}$. The values of $R_{\mathrm{p}}$ are $7.00 \times 10^{-4}$ and $6.29 \times$ $10^{-4} \mathrm{~mol} \mathrm{dm}^{-3} \mathrm{~s}^{-1}$ for the polymerizations with and without $1 \mathrm{wt} . \% \mathrm{Na}^{+}$-MMT, respectively. However, the value of $R_{\mathrm{p}}$ for the run with $9 \mathrm{mM}$ SDS and in the absence of both the $\mathrm{Na}^{+}$-MMT and additionally added $\mathrm{NaCl}$ is $5.98 \times 10^{-4} \mathrm{~mol} \mathrm{dm}^{-3} \mathrm{~s}^{-1}$. Thus, the ionic strength effect alone cannot account for the much stronger increased $R_{\mathrm{p}}$ arising from the use of 1 wt. $\% \mathrm{Na}^{+}$-MMT (see the $\left(R_{\mathrm{p}}-R_{\mathrm{p}, 0}\right) / R_{\mathrm{p}, 0}$ data for the run with $[\mathrm{SDS}]=9 \mathrm{mM}$ in Table 1$)$. Furthermore, the featureless XRD spectrum of the PS/Na ${ }^{+}$-MMT (93.3/6.7 (w/w)) sample obtained from the polymerization with $9 \mathrm{mM}$ SDS and $1 \mathrm{wt} . \% \mathrm{Na}^{+}$-MMT suggests that the probability for the regular structure of $\mathrm{Na}^{+}$-MMT platelets to weaken or even disappear after the completion of the polymerization is quite high (Fig. 5), which is consistent with the literature [16]. It is noteworthy that, at this level of $\mathrm{Na}^{+}$-MMT, the XRD instrument should be capable of detecting the multiple-layered 
(a)
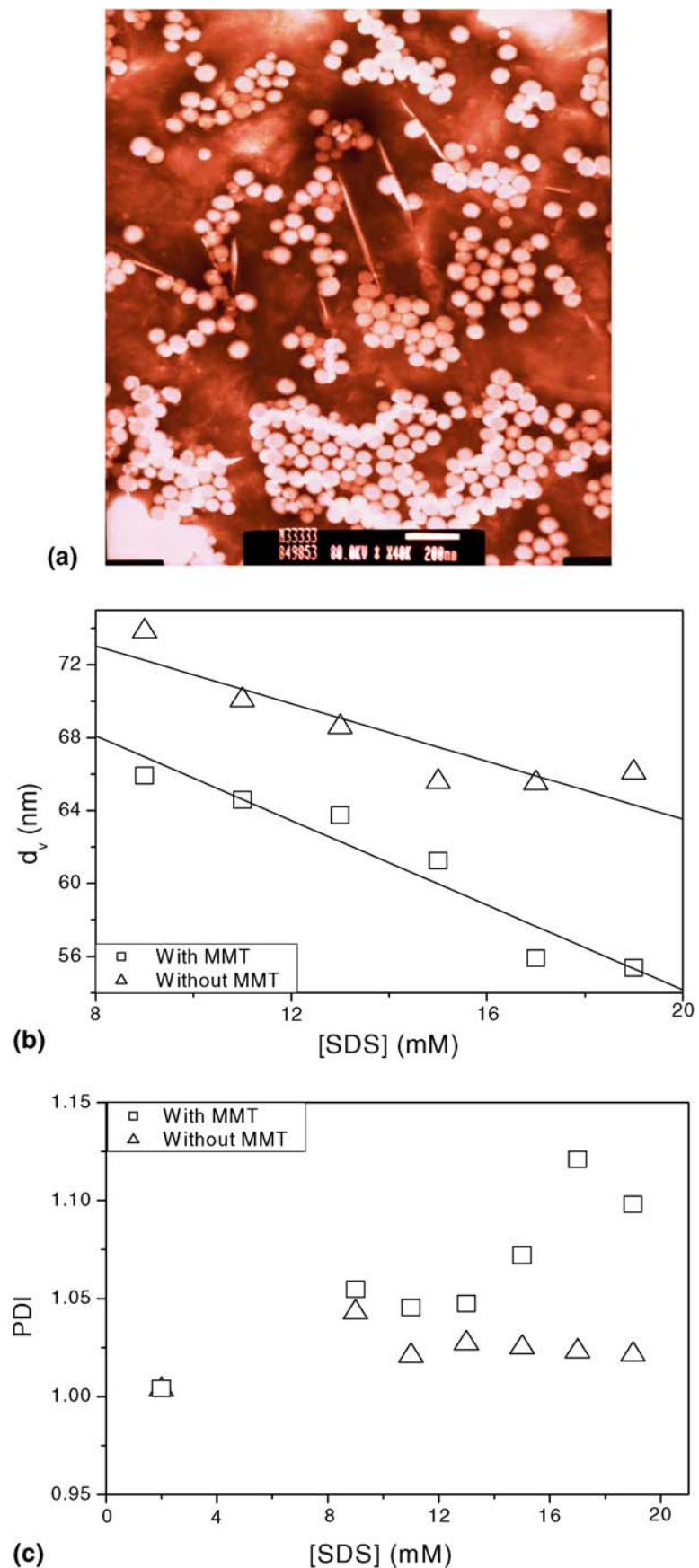

Fig. 4. (a) A representative TEM photograph for the $\mathrm{Na}^{+}$MMT-containing polymerization with $[\mathrm{SDS}]=13 \mathrm{mM}$; (b) final latex particle diameter as a function of the bulk SDS concentration; (c) polydispersity index of the particle size distribution as a function of the bulk SDS concentration. $\mathrm{Na}^{+}$-MMT $($ wt. $\%)=(\square) 1,(\triangle) 0$.

structure of $\mathrm{Na}^{+}$-MMT (if present) dispersed in the amorphous PS matrix. In addition, Table 1 shows that a significant increase in $R_{\mathrm{p}}$ was achieved when

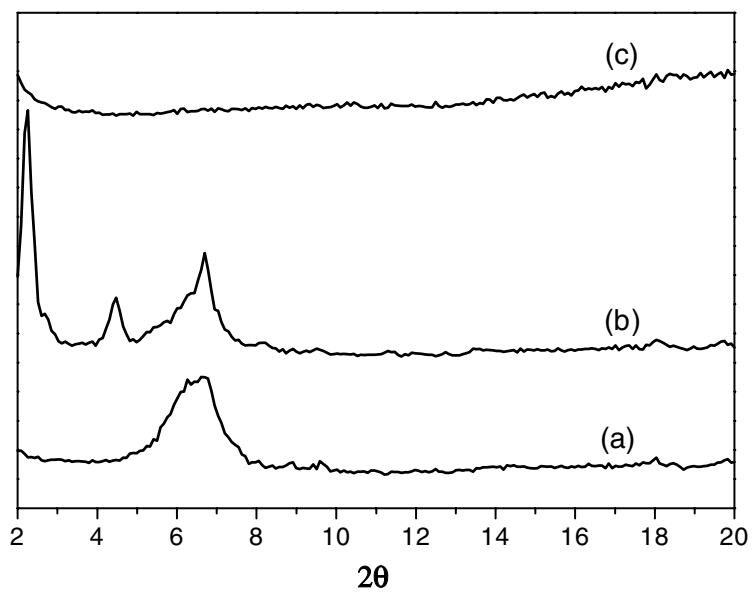

Fig. 5. X-ray powder diffraction spectra of (a) $\mathrm{Na}^{+}-\mathrm{MMT}$ dispersed in the aqueous solution of $2.66 \mathrm{mM} \mathrm{NaHCO}_{3}$, (b) $\mathrm{Na}^{+}$-MMT dispersed in the aqueous solution of $2.66 \mathrm{mM}$ $\mathrm{NaHCO}_{3}$ and $9 \mathrm{mM}$ SDS, and (c) the PS/ $\mathrm{Na}^{+}$-MMT (93.3/6.7 (w/w)) sample obtained from the polymerization with $2.66 \mathrm{mM}$ $\mathrm{NaHCO}_{3}, 9 \mathrm{mM}$ SDS and 1 wt. $\% \mathrm{Na}^{+}-\mathrm{MMT}$.

1 wt. $\% \mathrm{Na}^{+}$-MMT was added to the polymerization in the absence of micelles $([\mathrm{SDS}]=2 \mathrm{mM})$. All these results provide supporting evidence for the contribution of $\mathrm{Na}^{+}$-MMT to the enhanced polymerization rate.

$M_{\mathrm{w}}$ increases with increasing [SDS] for both the polymerizations with and without $\mathrm{Na}^{+}-\mathrm{MMT}$ (Fig. 6). This is attributed to the enhanced segregation of radicals inside the particles with increasing [SDS] (i.e., $\left.N_{\mathrm{p}}\right)\left(N_{\mathrm{p}} \sim[\mathrm{SDS}]^{0.47}, r^{2}=0.9350\right.$ for the runs without $\mathrm{Na}^{+}$-MMT). The segregation effect reduces the probability of bimolecular termination via the entry of a radical into the particle already containing one radical. Furthermore, at constant [SDS], the $M_{\mathrm{w}}$ of the polymerization with $\mathrm{Na}^{+}$MMT is larger than that of the counterpart without $\mathrm{Na}^{+}-\mathrm{MMT}$. One possible explanation for this observation is the competitive absorption of radicals by $\mathrm{Na}^{+}$-MMT platelets that further depresses the bimolecular termination reaction in the latex particles. It should be noted that the difference in $M_{\mathrm{w}}$ between the polymerizations with and without $\mathrm{Na}^{+}$-MMT increases with decreasing [SDS]. This shows supporting evidence of the important role of $\mathrm{Na}^{+}$-MMT platelets for the polymerizations stabilized by relatively low levels of surfactant.

The zeta potential $(\zeta)$ of the latex particles and $\mathrm{Na}^{+}$-MMT platelets (if present) data are shown in Fig. 7. The absolute value of $\zeta$ increases with increasing $[\mathrm{SDS}]$ for the polymerizations in the 


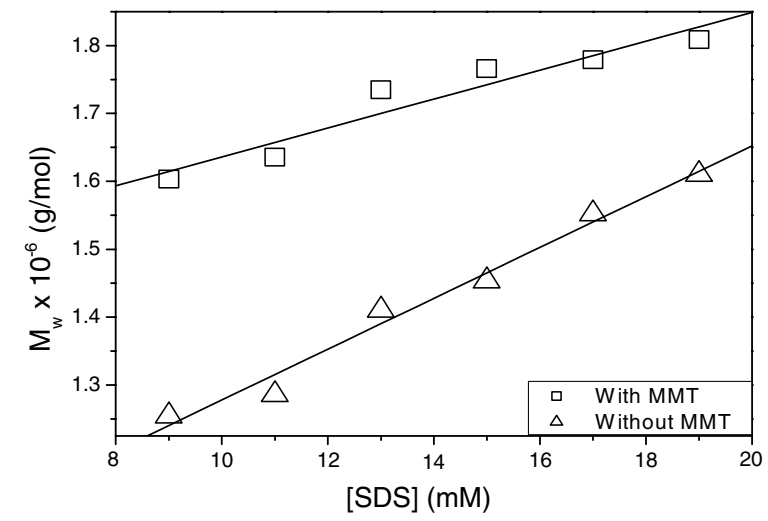

Fig. 6. Polymer molecular weight as a function of the bulk SDS concentration. $\mathrm{Na}^{+}-\mathrm{MMT}($ wt. $\%)=(\square) 1,(\triangle) 0$.

absence of $\mathrm{Na}^{+}$-MMT, whereas a reverse trend is observed for the polymerizations in the presence of $\mathrm{Na}^{+}$-MMT. Although the data are somewhat scattered for the polymerizations with $\mathrm{Na}^{+}$-MMT $\left(r^{2}=0.8057\right.$, Fig. 8), the $\zeta$ data correlate reasonably well with the particle surface charge density, $[\mathrm{SDS}] /\left(\pi d_{\mathrm{v}}^{2} N_{\mathrm{p}}\right)$. For the purpose of demonstration only, the assumption that all the polymer chains form in the latex particles has been made to construct the $\zeta$ vs. $[\mathrm{SDS}] /\left(\pi d_{\mathrm{v}}^{2} N_{\mathrm{p}}\right)$ plot for the polymerizations with $\mathrm{Na}^{+}-\mathrm{MMT}$. It is postulated that the scattered data reflect the influence of $\mathrm{Na}^{+}$-MMT on the electrophoretic properties. As expected, $\zeta$ increases with increasing particle surface charge density (Fig. 8).

In the presence of $\mathrm{Na}^{+}$-MMT, $R_{\mathrm{p}}$ during the constant reaction rate period can be expressed as

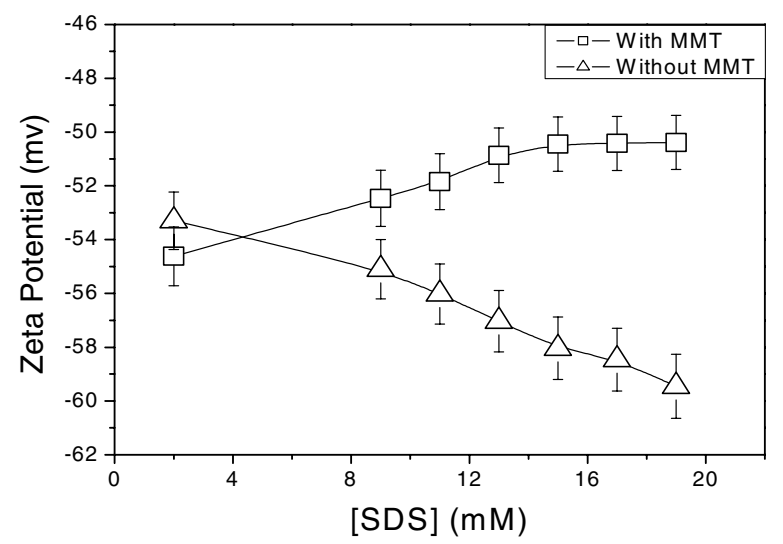

Fig. 7. Zeta potential of latex particles and $\mathrm{Na}^{+}-\mathrm{MMT}$ platelets (if present) as a function of the bulk SDS concentration. $\mathrm{Na}^{+}$MMT $($ wt. $\%)=(\square) 1,(\triangle) 0$.

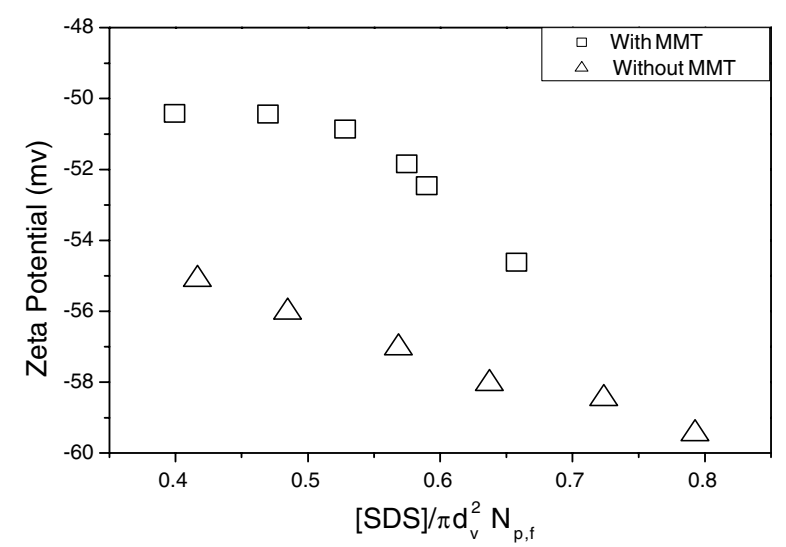

Fig. 8. Zeta potential of latex particles and $\mathrm{Na}^{+}$-MMT platelets (if present) as a function of the surface charge density. $\mathrm{Na}^{+}$$\operatorname{MMT}($ wt. $\%)=(\square) 1,(\triangle) 0$.

$$
\begin{aligned}
& R_{\mathrm{p}}= R_{\mathrm{p}, 0}+R_{\mathrm{p}, \mathrm{MMT}}=k_{\mathrm{p}, 0}[\mathrm{M}]_{\mathrm{p}}\left(n_{\mathrm{p}} N_{\mathrm{p}, 0} / N_{\mathrm{A}}\right) \\
&+k_{\mathrm{p}, \mathrm{MMT}}[\mathrm{M}]_{\mathrm{MMT}}\left(n_{\mathrm{MMT}} N_{\mathrm{MMT}} / N_{\mathrm{A}}\right) \\
& N_{\mathrm{p}, 0}= {\left[W_{\mathrm{m}} X_{\mathrm{f}} /\left(\pi / 6 d_{\mathrm{v}}^{3} \rho_{\mathrm{p}} W_{\mathrm{w}}\right)\right] \omega } \\
& N_{\mathrm{MMT}}=N_{\mathrm{MMT}, \mathrm{t}} / n_{\mathrm{agg}, \mathrm{MMT}} \\
& n_{\mathrm{p}}=1 / 2\left\{-\alpha^{\prime} / m+\left[\left(\alpha^{\prime} / m\right)^{2}+2 \alpha^{\prime} / m\right]^{1 / 2}\right\} \\
& \text { when } n_{\mathrm{p}} \leqq 0.5
\end{aligned}
$$

where the subscripts 0 and MMT represent the related kinetic parameters associated with the latex particles and $\mathrm{Na}^{+}$-MMT platelets, respectively. $W_{\mathrm{m}}$ is the total monomer weight, $X_{\mathrm{f}}$ the final fractional monomer conversion, $\rho_{\mathrm{p}}$ the polymer density, $W_{\mathrm{w}}$ the total water weight, $\omega$ the degree of contribution of the polymerization in latex particles $(0 \leqq \omega \leqq 1)$. $N_{\text {MMT }}$ is the number of $\mathrm{Na}^{+}$-MMT platelets per unit liter water, $N_{\mathrm{MMT}, \mathrm{t}}$ the total number of the smallest units of multiple-layered $\mathrm{Na}^{+}$MMT platelets (each platelet with approximate dimensions of $100 \times 100 \times 1 \mathrm{~nm}^{3}$ and total particle surface area of $2.04 \times 10^{4} \mathrm{~nm}^{2}$ [23]), and $n_{\mathrm{agg}, \mathrm{MMT}}$ the number of platelets per stack. The empirical Eq. (5) derived by Nomura [24] was used to calculate $n_{\mathrm{p}} \cdot \alpha^{\prime}\left[=\rho_{\mathrm{i}} v_{\mathrm{p}} /\left(k_{\mathrm{t}} N_{\mathrm{p}}\right)\right]$ is the dimensionless group associated with the absorption of radicals by the latex particles, $m\left(=k_{\text {des }} v_{\mathrm{p}} / k_{\mathrm{t}}\right)$ is the dimensionless group associated with the desorption of radicals out of the particles, $\rho_{\mathrm{i}}$ is equal to $2 f k_{d}[\mathrm{I}], f$ is defined as the initiator efficiency factor in the polymerizations containing $1 \mathrm{wt} . \% \mathrm{Na}^{+}$-MMT that takes into account the effect of the presence of $1 \mathrm{wt} . \% \mathrm{Na}^{+}$MMT on the absorption of free radicals by the latex particles, $k_{d}\left[=6.06 \times 10^{16} \exp (-140,167 / R T) \mathrm{s}^{-1}\right]$ [25] is the initiator decomposition rate constant, [I] 
is the initiator concentration, $v_{\mathrm{p}}$ is the volume of a particle, $k_{\mathrm{t}}\left[=8.2 \times 10^{9} \exp (-14,510 / R T) \mathrm{dm}^{3} \mathrm{~mol}^{-1}\right.$ $\mathrm{s}^{-1}$ ] [26] is the termination rate constant, and $k_{\mathrm{des}}\left[=k_{\mathrm{des}}^{\prime} /\left(v_{\mathrm{p}}\right)^{2 / 3}\right] \quad[27]$ is the desorption rate constant. In addition to the above parameters, the following parameters obtained from the literature or estimated in this work were used to carry out computer simulations: $k_{\mathrm{p}, 0}=k_{\mathrm{p}, \mathrm{MMT}}=4.27 \times$ $10^{7} \exp (-32,510 / R T) \mathrm{dm}^{3} \mathrm{~mol}^{-1} \mathrm{~s}^{-1}[28], \quad[\mathrm{M}]_{\mathrm{p}}=$ $[\mathrm{M}]_{\mathrm{MMT}}=5.2 \mathrm{M}[29],[\mathrm{I}]=2.59 \mathrm{mM}, k_{\mathrm{des}}^{\prime}=(1.94 \pm$ $0.86) \times 10^{-11} \mathrm{~cm}^{2} \mathrm{~s}^{-1}$ at $70{ }^{\circ} \mathrm{C}$ based on the kinetic data obtained from the polymerizations in the absence of $\mathrm{Na}^{+}$-MMT in this study, and $N_{\mathrm{MMT}, \mathrm{t}}=$ $4.42 \times 10^{17} \mathrm{dm}^{-3}$ estimated by dividing the total $\mathrm{Na}^{+}$-MMT platelet surface area $\left(7.5 \times 10^{20} \mathrm{~nm}^{2}\right.$ $\mathrm{g}^{-1} \times 12.02 \mathrm{~g} \mathrm{dm}^{-3}$ ) by $2.04 \times 10^{4} \mathrm{~nm}^{2}$, where the specific $\mathrm{Na}^{+}-\mathrm{MMT}$ platelet surface area $(7.5 \times$ $10^{20} \mathrm{~nm}^{2} \mathrm{~g}^{-1}$ ) was taken from the literature $[30,31]$.

Eqs. (2)-(5) were first used to qualitatively study the effect of the flux of free radicals toward the latex particles $(f=0.1,0.3$ or 0.5$)$ on the polymerization mechanisms and kinetics in the presence of $1 \mathrm{wt} . \%$ $\mathrm{Na}^{+}$-MMT. Some representative contour plots of the $n_{\text {agg,MMT }}$ vs. $\omega$ data for the polymerizations with $[\mathrm{SDS}]=13 \mathrm{mM}$ and $n_{\mathrm{MMT}}=0.5$ are shown in Fig. 9a. At constant $f, n_{\text {agg,MMT }}$ increases with increasing $\omega$ and this trend becomes more pronounced when $f$ increases from 0.1 to 0.5 . This is simply due to the fact that the larger the contribution of polymerization in the latex particles (i.e., the larger value of $\omega$ or $\left.N_{\mathrm{p}, 0}\right)$ is, the slower the rate of polymerization in the $\mathrm{Na}^{+}$-MMT platelets (i.e., the larger value of $n_{\text {agg,MMT }}$ or the smaller value of $N_{\mathrm{MMT}}$ ) is required to achieve the same total polymerization rate $\left(R_{\mathrm{p}}\right)$. It should be noted that the smaller the value of $n_{\mathrm{agg}, \mathrm{MMT}}$, the better the dispersion of $\mathrm{Na}^{+}$MMT platelets in the reaction system. $\mathrm{Na}^{+}-\mathrm{MMT}$ becomes completely exfoliated when $n_{\text {agg,MMT }}$ approaches unity. It was reported that the pristine $\mathrm{Na}^{+}-\mathrm{MMT}$ existed in agglomerates of $1-10 \mu \mathrm{m}$ in diameter, which comprised primary units of about 8-10 layered silicate platelets in each stack $\left(n_{\text {agg,MMT }}=8-10\right)$ [32]. The $\mathrm{Na}^{+}$-MMT subject to intensive shear force and strong interactions between the surface active radicals and the highly swollen platelets should exist at least in the primary unit form and, therefore, have a $n_{\mathrm{agg}, \mathrm{MMT}}$ value smaller than 10. Similar results were also observed for the polymerizations with $[\mathrm{SDS}]=13 \mathrm{mM}$ and $n_{\mathrm{MMT}}=0.75$ and 1 (Fig. 9b and c). These preliminary simulation results also suggest that lower flux of free radicals toward the latex particles (i.e., smaller values of $f$ )

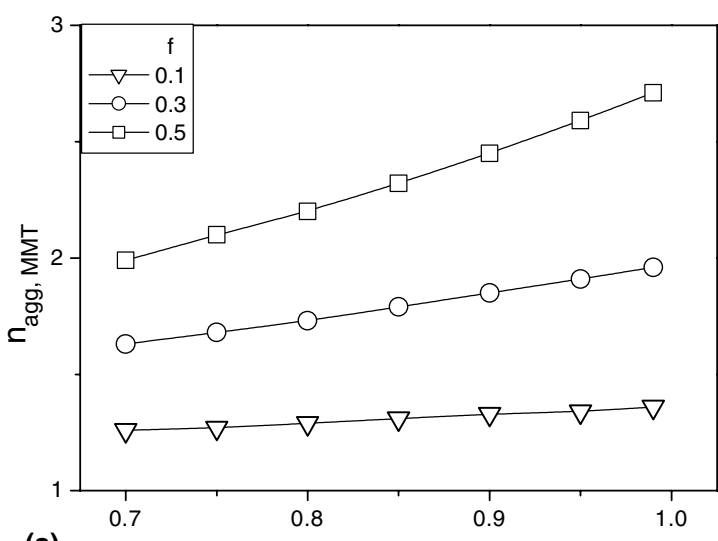

(a)
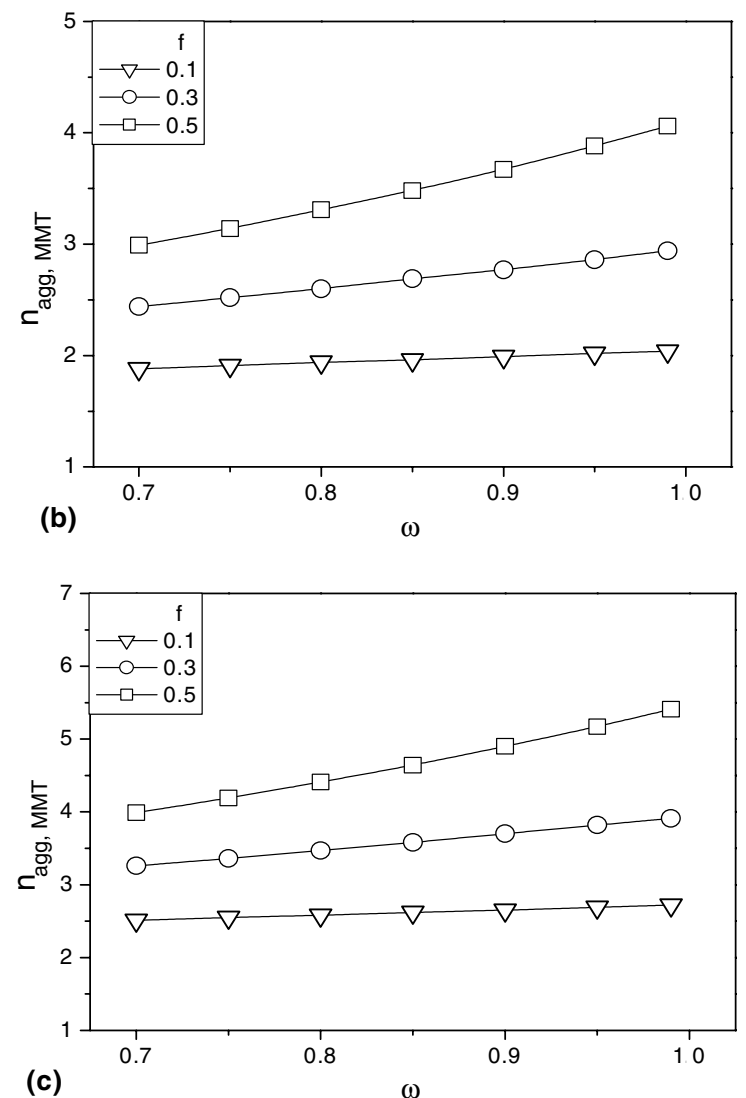

Fig. 9. Contour plots of the $n_{\mathrm{agg}, \mathrm{MMT}}$ vs. $\omega$ data for the polymerizations with $1 \mathrm{wt} . \% \mathrm{Na}^{+}-\mathrm{MMT},[\mathrm{SDS}]=13 \mathrm{mM}$ and different values of $f$. (a) $n_{\mathrm{MMT}}=0.5$; (b) $n_{\mathrm{MMT}}=0.75$; (c) $n_{\mathrm{MMT}}=1.0$. (f) ( $\left.\square\right) 0.1,(\bigcirc) 0.3,(\nabla) 0.5$.

and less contribution of the polymerization in the latex particles (i.e., smaller values of $\omega$ ( or $N_{\mathrm{p}, 0}$ ) and $n_{\mathrm{MMT}}$ ) promote the intercalation or even exfoliation of $\mathrm{Na}^{+}$-MMT platelets in the aqueous phase.

This model was then used to study the effect of $[\mathrm{SDS}](9,11,13,15$ and $17 \mathrm{mM})$ on the polymeri- 
zation mechanisms and kinetics in the presence of 1 wt. $\% \mathrm{Na}^{+}$-MMT. The parameter $f$ was kept constant at 0.3 in this series of computer simulations. Fig. 10 shows some representative contour plots of the $n_{\text {agg,MMT }}$ vs. $\omega$ data for the polymerizations

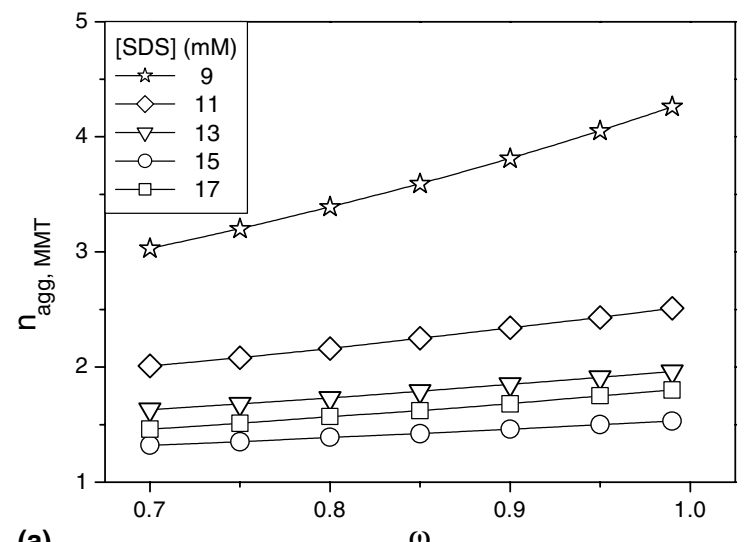

(a)

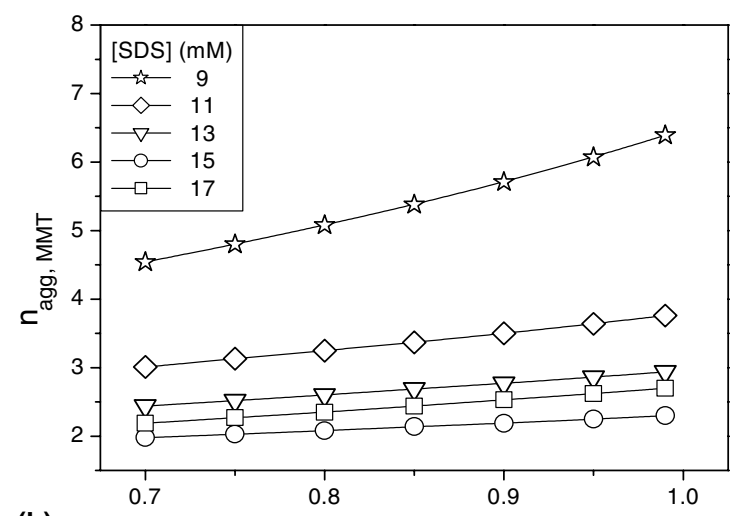

(b)

$\omega$

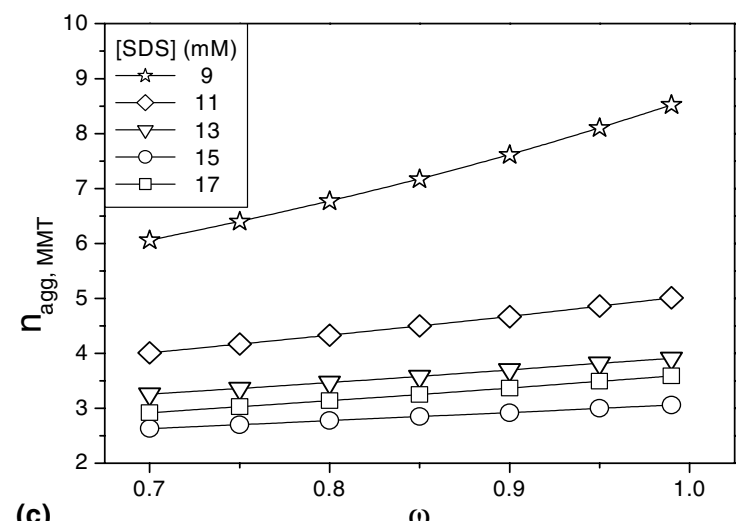

Fig. 10. Contour plots of the $n_{\text {agg,MMT }}$ vs. $\omega$ data for the polymerizations with $1 \mathrm{wt} . \% \mathrm{Na}^{+}$-MMT, $f=0.3$ and various bulk concentrations of SDS. (a) $n_{\mathrm{MMT}}=0.5$; (b) $n_{\mathrm{MMT}}=0.75$; (c) $n_{\mathrm{MMT}}=1.0 .[\mathrm{SDS}](\mathrm{mM}):($ 汭 $9,(\diamond) 11,(\nabla) 13,(\bigcirc) 15,(\square) 17$. with different values of $[\mathrm{SDS}]$ and $n_{\mathrm{MMT}}$. At $n_{\mathrm{MMT}}=0.75$ and constant [SDS], $n_{\mathrm{agg}, \mathrm{MMT}}$ increases with increasing $\omega$ and this trend becomes more pronounced when [SDS] decreases from 17 to $9 \mathrm{mM}$ (Fig. 10b). This is because the larger the contribution of the polymerization in the latex particles (i.e., the larger value of $\omega$ or $N_{\mathrm{p}, 0}$ ) is, the slower the rate of polymerization in the $\mathrm{Na}^{+}$MMT platelets (i.e., the larger value of $n_{\mathrm{agg}, \mathrm{MMT}}$ or the smaller value of $N_{\mathrm{MMT}}$ ) is required to achieve the same total polymerization rate $\left(R_{\mathrm{p}}\right)$. At constant $\omega, n_{\text {agg,MMT }}$ decreases with increasing [SDS], but this effect becomes smaller when [SDS] increases from 9 to $17 \mathrm{mM}$. These simulation results again indicate that the effect of $\mathrm{Na}^{+}$-MMT on the polymerization kinetics becomes more important for the polymerizations stabilized by lower levels of SDS. In addition, the calculated results suggest that the probability of intercalating or even exfoliating the $\mathrm{Na}^{+}$-MMT platelets increases with increasing [SDS]. Thus, the results in Fig. $10 \mathrm{~b}$ are reasonable for the $\mathrm{Na}^{+}$-MMT-containing polymerizations with $[\mathrm{SDS}]=9-17 \mathrm{mM}$. The contour plots at $n_{\mathrm{MMT}}=0.5$ (Fig. 10a) and at $n_{\mathrm{MMT}}=1.0$ (Fig. $10 \mathrm{c}$ ) exhibit very similar characteristic to the contour plot at $n_{\mathrm{MMT}}=0.5$ (Fig. 10b), but $n_{\text {agg,MMT }}$ shifts toward a region with larger values when $n_{\mathrm{MMT}}$ increases from 0.5 to 1.0 (Fig. 10).

It is noteworthy that the $n_{\text {agg,MMT }}$ value may decrease and, consequently, $N_{\mathrm{MMT}}$ may increase with the progress of polymerization. In addition, the location (the interlayer between two adjacent $\mathrm{Na}^{+}$-MMT platelets or the surfaces of $\mathrm{Na}^{+}$-MMT agglomerates) of the polymerization associated with $\mathrm{Na}^{+}$-MMT and the morphology of $\mathrm{Na}^{+}$-MMT platelets may also change significantly during polymerization. All these factors will make the polymerization mechanisms and kinetics even more complicated. It should be noted that Eqs. (2)-(5) only represent a preliminary model in an attempt to simulate the ST emulsion polymerization in the presence of $1 \mathrm{wt} . \% \mathrm{Na}^{+}-\mathrm{MMT}$. In order to gain an insight into the ST emulsion polymerization in the presence of $\mathrm{Na}^{+}$-MMT, more independent experiments are required to determine some of the parameters.

\section{Conclusions}

The influence of the pristine $\mathrm{Na}^{+}$-MMT platelets (1 wt.\%) on the ST emulsion polymerizations with 
different concentrations of SDS ([SDS $]=2-19 \mathrm{mM})$ was investigated. For comparison, the corresponding polymerizations in the absence of $\mathrm{Na}^{+}-\mathrm{MMT}$ were also carried out. The experimental data showed that, at constant [SDS], the polymerization rate is faster for the run with $\mathrm{Na}^{+}$-MMT compared to the counterpart without $\mathrm{Na}^{+}-\mathrm{MMT}$. This was attributed to the higher concentration of micelles (if present) for particle nucleation and the $\mathrm{Na}^{+}$. MMT platelets served as reaction loci. Micelle nucleation predominates in the ST emulsion polymerizations with $[\mathrm{SDS}] \geqq 13 \mathrm{mM}$. On the other hand, the contribution of the polymerization associated with $\mathrm{Na}^{+}$-MMT platelets increases significantly when [SDS] decreases from 13 to $9 \mathrm{mM}$. When [SDS] is below the CMC, homogeneous nucleation controls the polymerization kinetics. Moreover, the contribution of $\mathrm{Na}^{+}$-MMT platelets to the polymerization kinetics is even comparable to the run without $\mathrm{Na}^{+}$-MMT. The differences in the resultant polymer particle size, polymer molecular weight and zeta potential between the polymerizations in the presence and absence of $1 \mathrm{wt} . \%$ $\mathrm{Na}^{+}$-MMT were investigated. A preliminary model was developed to qualitatively study the effect of the presence of $1 \mathrm{wt} . \% \mathrm{Na}^{+}$-MMT on the polymerization mechanisms and kinetics.

\section{References}

[1] Harkins WD. J Chem Phys 1945;13:381.

[2] Harkins WD. J Chem Phys 1946;14:47.

[3] Harkins WD. J Am Chem Soc 1947;69:1428.

[4] Smith WV. J Am Chem Soc 1948;70:3695.

[5] Smith WV, Ewart RH. J Chem Phys 1948;16:592.

[6] Smith WV. J Am Chem Soc 1949;71:4077.
[7] Priest WJ. J Phys Chem 1952;56:1977.

[8] Roe CP. Ind Eng Chem 1968;60:20.

[9] Fitch RM, Tsai CH. In: Fitch RM, editor. Polymer colloids. New York: Plenum Press; 1971. p. 73.

[10] Fitch RM, Tsai CH. In: Fitch RM, editor. Polymer colloids. New York: Plenum Press; 1971. p. 103.

[11] Fitch RM. Br Polym J 1973;5:467.

[12] Choi YS, Choi MH, Wang KH, Kim SO, Kim YK, Chung IJ. Macromolecules 2001;34:8978.

[13] Choi YS, Wang KH, Xu M, Chung IJ. Chem Mater 2002;14:2936.

[14] Kim TH, Jang LW, Lee DC, Choi HJ, Jhon MS. Macromol Rapid Commun 2002;23:191.

[15] Kim BH, Jung JH, Hong SH, Joo J, Epstein AJ, Mizoguchi $\mathrm{K}$, et al. Macromolecules 2002;35:1419.

[16] Kim YK, Choi YS, Wang KH, Chung IJ. Chem Mater 2002;14:4990.

[17] Goddard ED, Benson GC. Can J Chem 1957;35:986.

[18] Mukerjee P, Mysels KJ, Dulin CI. J Phys Chem 1958;62:1390

[19] Chang HC, Lin YY, Chern CS, Lin SY. Langmuir 1998;14:6632.

[20] Hayase K, Hayano S. Bull Chem Soc Jpn 1977;50:83.

[21] Jain AK, Singh RPB. J Colloid Interf Sci 1981;81:536.

[22] Hunter RJ. Foundations of colloid science, vol. 1. New York: Oxford; 1989. p. 598.

[23] Usuki A, Hasegawa N, Kadoura H, Okamoto T. Nano Letters 2001;1:271.

[24] Nomura M. In: Piirma I, editor. Emulsion polymerization. New York: Academic; 1982. p. 191.

[25] Kolthoff IM, Miller IK. J Am Chem Soc 1951;73:3055.

[26] Matheson MS, Auer EE, Bevilacqua EB, Hart EJ. J Am Chem Soc 1951;73:1700.

[27] Lee HC, Poehlein GW. Polym Process Eng 1987;5:37.

[28] Gilbert RG. Pure Appl Chem 1996;68:1491.

[29] Bartholome E, Gerrens H, Herbeck R, Weitz HM. Z Elektrochem 1956;60:334.

[30] Lefebvre Y, Lacelle S, Jolicoeur C. J Mater Res 1992;7:1888.

[31] Celis R, Cornejo J, Hermosin MC. Clay Miner 1996;31:355.

[32] Akelah A, Moer A. J Appl Polym Sci: Appl Polym Symp 1994;55:153. 